\title{
ANALISIS KEKUATAN MATERIAL BAJA S45C PADA PERENCANAAN ARM DAN POROS PENYANGGA DISC BRAKE BELAKANG MOTOR SKUTER 2 TAK 150 CC
}

\author{
Strength Analysis of Material Steel S45C on the Arm and Cantilever Shaft Rear Disc Brake Planning \\ of Scooter Motorcycle 2 Stroke 150 CC
}

\author{
Alfian Anggraista ${ }^{1}$, Nely Ana Mufarida ${ }^{2}$, Ardhi Fathonisyam Putra Nusantara ${ }^{3}$ \\ 1,2,3 Program Studi Teknik Mesin, Fakultas Teknik, Universitas Muhammadiyah Jember \\ Email: ${ }^{1)}$ alfiananggraista@gmail.com
}

\begin{abstract}
ABSTRAK
Beberapa anggota komunitas sepeda motor sangat senang memodifikasi sepeda motornya, mulai dari body, mesin, pengapian, pembakaran sampai sistem pengereman. Sebagian besar motor vespa produksi piaggio dengan sistem 2 tak masih menggunakan tipe rem tromol, dimana tipe rem ini tentunya memiliki kelebihan dan kekurangan. Akan tetapi ada sebagian pengguna vespa yang telah memodifikasi motornya sehingga mampu untuk melaju melebihi kecepatan maksimum. Dimana kecepatan maksimum vespa yaitu $100 \mathrm{~km} / \mathrm{jam}$, oleh karena itu di butuhkan sistem pengereman yang baik, agar saat motor digunakan pada kecepatan tinggi pengemudi tetap dapat mengendalikan arah laju kendaraan. Hasil yang diperoleh dari penelitian ini yaitu berdasarkan hasil simulasi stress, strain, displacement dan melakukan perbandingan nilai stress dengan angka keamanan menurut teori kegagalan MDET (Mises Distortion-Energy Theory) pada arm dan poros penyangga disc brake menggunakan material baja S45C didapat angka keamanan untuk arm penyangga sebesar $105 \mathrm{Mpa}$ dan poros penyangga 52,5 Mpa, tegangan maksimal pada arm penyangga sebesar $9.994 \mathrm{Mpa}$, strain 3.774e-5 Mpa dan displacement 5,791e-3 mm sedangkan tegangan maksimal pada poros penyangga sebesar $24.621883 \mathrm{Mpa}$, strain $7.705 \mathrm{e}-2 \mathrm{Mpa}$ dan displacement 1.381 $\mathrm{mm}$.
\end{abstract}

Kata kunci: Arm dan Poros Penyangga Disc Brake, Perencanaan Elemen Mesin (Machine Design), Simulasi, Teori Kegagalan, Baja S45C.

\begin{abstract}
Some members of the motorcycle community are very happy to modify their bikes, ranging from body, engine, ignition, combustion to braking system. Most vespa motor production piaggio with 2-stroke system is still using the type of brake tromol, where type of brake is of course has advantages and disadvantages. However, there are some vespa users who have modified the bike so as to be able to drive beyond the maximum speed. Where the maximum speed of the vespa is $100 \mathrm{~km} / \mathrm{h}$, therefore in need a good braking system, so that when the motor is used at high speed the driver can still control the direction of vehicle speed. The results obtained from this study are based on the results of stress simulation, strain, displacement and comparison of stress values with security figures according to MDET failure theory (Mises Distortion-Energy Theory) on arm and disc brake cantilever shaft using S45C steel material obtained security number for cantilever arm of $105 \mathrm{MPa}$ and a $52.5 \mathrm{Mpa}$ cantilever shaft, maximal stress on the supporting arm of $9.994 \mathrm{MPa}, 3.774 \mathrm{e}-5 \mathrm{MPa}$ strain and displacement of $5.791 \mathrm{e}-3 \mathrm{~mm}$ while the maximal stress on the cantilever shaft is $24.621883 \mathrm{Mpa}$, strain $7.705 e-2 \mathrm{Mpa}$ and displacement of $1,381 \mathrm{~mm}$.
\end{abstract}

Keywords: Arm and Cantilever Shaft Disc Brake, Machine Design Planning, Simulation, Failure Theory, S45C Steel. 


\section{PENDAHULUAN}

\section{Latar Belakang}

Sebagian besar motor vespa produksi piaggio dengan sistem 2 tak masih menggunakan tipe rem tromol, dimana tipe rem ini tentunya memiliki kelebihan dan kekurangan. Akan tetapi ada sebagian pengguna vespa yang telah memodifikasi motornya sehingga mampu untuk melaju melebihi kecepatan maksimum. Dimana kecepatan maksimum vespa yaitu $100 \mathrm{~km} / \mathrm{jam}$, oleh karena itu di butuhkan sistem pengereman yang baik, agar saat motor digunakan pada kecepatan tinggi pengemudi tetap dapat mengendalikan arah laju kendaraan.

Disc brake ini nantinya akan dipasang pada tromol vespa ditambahankan dengan arm penyangga yang dikaitkan pada crankcase mesin guna mendapatkan kekuatan atau ketahan yang cukup untuk menahan beban saat terjadi getaran ketika vespa berjalan. Untuk itu perlu adanya perhitungan kekuatan dari material yang di gunakan sebagai arm penyangga agar pengguna motor dapat tenang dan tidak khawatir terjadi kerusakan pada disc brake modifikasi ini saat berkendara baik jarak dekat maupun jarak jauh dan juga dalam kondisi jalan yang baik maupun kondisi jalan yang kurang baik atau berlubang.

\section{Rumusan Masalah}

Berdasarkan latar belakang diatas, maka kita dapat merumuskan masalah, antara lain :

(1) Apakah baja S45C aman untuk dijadikan bahan pembuatan arm dan poros penyangga disc brake?

(2) Bagaimana hasil simulasi stress, strain dan displacement menggunakan software FEM (Finite Element Method)?

\section{Batasan Masalah}

Penelitian ini hanya memfokuskan pada perhitungan kekuatan material arm dan poros penyangga disc brake.

(1) Tidak melakukan perhitungan kekuatan material pada tromol vespa.

(2) Tidak melakukan perbandingan antara rem tromol vespa dengan rem cakram.

\section{Tujuan Penelitian}

(1) Mengetahui kekuatan material baja S45C yang dijadikan sebagai bahan dari arm dan poros penyangga disc brake.

(2) Mengetahui tingkat keamanan modifikasi yang dijadikan sebagai arm dan poros penyangga.

(3) Mengetahui kekuatan dari arm dan poros penyangga disc brake ketika mendapat pembebanan merata.

\section{TINJAUAN PUSTAKA \\ Tegangan}

Apabila suatu benda yang dikenai gaya atau beban, maka akan menyebabkan gaya internal yang ada pada benda menahan gaya yang timbul dari luar. Dimana gaya internal per luas area ini dinamakan unit stress atau sederhananya adalah tegangan (stress). Dilambangkan dengan huruf yunani $(\sigma)$ sigma, secara matematisnya ialah,

$$
\sigma=\frac{P}{A} \text { (Mpa) }
$$

Dimana:

$\sigma=$ Tegangan (Mpa)

$\mathrm{P}=$ Gaya atau beban yang bekerja pada benda $(\mathrm{N})$

$\mathrm{A}=$ Luas area benda $\left(\mathrm{mm}^{2}\right)$

\section{Tegangan Geser Puntir}

Ketika sebuah mesin dikenai sebuah gaya atau beban yang sama dan sejajar dengan bidang (momen puntir), maka dikatakan bagian mesin itu dikenai Torsi. Dan sebuah tegangan yang diakibatkan oleh torsi disebut tegangan geser puntir seperti yang diilustrasikan pada Gambar 1. Kekuatan dari sebuah poros adalah torsi maksimum yang ditransmisikan oleh poros tersebut, untuk menghitung kekuatan poros dapat menggunakan persamaan diatas, tenaga yang ditransmisikan oleh poros (dinyatakan dalam watt),

$$
P=\frac{2 \pi n \cdot T}{60}=T . \omega
$$

Dimana:

$\mathrm{P}=$ Besar tenaga yang digerakkan oleh poros (watt) $\mathrm{n}=$ Putaran $(\mathrm{rpm})$

$\omega=$ Kecepatan sudut $(\mathrm{rad} / \mathrm{s})$

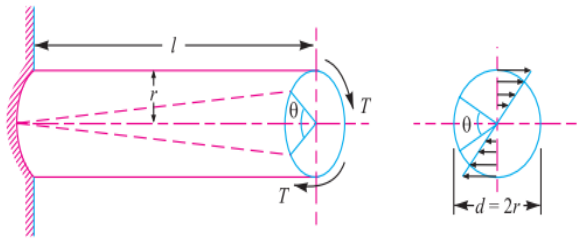

Gambar 1. Tegangan geser puntir ((R.S. Khurmi)

\section{Teori Kegagalan MDET (Mises Distortion-Energy Theory)}

Dengan suatu pengetahuan hanya pada tegangan luluh (yield) dari suatu material, teori kegagalan ini memprediksi "ductile yielding" dibawah suatu kombinasi pembebanan, dengan akurasi lebih baik daripada teori-teori kegagalan lainnya.

Teori kegagalan ini di analisa pertama melalui tegangan oktahedral, sehingga disebut sebagai teori kegagalan geser oktahedral maksimum yang terjadi melebihi harga limit yang diketahui dari hasil test tarik material standar dengan beban uniaksial. Agar pada slinder dinding tipis berada dalam kondisi aman menurut MDET haruslah dipenuhi:

$$
\sigma_{\mathrm{eq}} \leq \frac{S_{y}}{S F}
$$

Dimana:

$\sigma_{\mathrm{eq}}=\sqrt{\sigma_{1}^{2}+\sigma_{2}^{2}-\sigma_{1} \cdot \sigma_{2}}$

$\sigma_{1}=\sigma_{\mathrm{t}}=$ Tegangan tangensial, dan

$\sigma_{2}=\sigma_{a}=$ Tegangan aksial (Mhd. Daud Pinem, 2010) 


\section{METODE PENELITIAN}

Penelitian ini menggunakan simulasi dengan bantuan software CAD (Computer Aided Design) untuk pemodelan komponen dan software FEM (Finite Element Methode) untuk simulasi. Langkah awal simulasi ini adalah pengukuran komponen-komponen dan pemodelan komponen menggunakan software CAD (Computer Aided Design) kemudian proses perhitungan simulasi dengan software FEM (Finite Element Method).

\section{Alat dan Bahan}

Adapun alat-alat dan bahan yang digunakan dalam analisa simulasi kekuatan material ini antara lain:

\section{Alat}

(1) Jangka Sorong (ketelitian 0.05)

(2) Meteran

\section{Bahan}

(1) Arm penyangga disc brake

(2) Baja S45C (spesifikasi detail ditunjukkan Gambar 2)

(3) Poros Penyangga Disc Brake

(4) Vespa PX 150

\begin{tabular}{|l|l|l|}
\hline Property & Value & Units \\
\hline Elastic Modulus & 200000 & $\mathrm{~N} / \mathrm{mm}^{\wedge} 2$ \\
\hline Poisson's Ratio & 0.29 & $\mathrm{~N} / \mathrm{A}$ \\
\hline Shear Modulus & 80000 & $\mathrm{~N} / \mathrm{mm}^{\wedge} 2$ \\
\hline Mass Density & 7800 & $\mathrm{~kg} / \mathrm{m}^{\wedge} 3$ \\
\hline Tensile Strength & 680 & $\mathrm{~N} / \mathrm{mm}^{\wedge} 2$ \\
\hline Compressive Strength & & $\mathrm{N} / \mathrm{mm}^{\wedge} 2$ \\
\hline Yield Strength & 420 & $\mathrm{~N} / \mathrm{mm}^{\wedge} 2$ \\
\hline Thermal Expansion Coefficient & $1.1 \mathrm{e}-005$ & $/ \mathrm{K}$ \\
\hline Thermal Conductivity & 14 & $\mathrm{~W} /(\mathrm{m} \cdot \mathrm{K})$ \\
\hline Specific Heat & 440 & $\mathrm{~J} /(\mathrm{kg} \cdot \mathrm{K})$ \\
\hline Material Damping Ratio & & $\mathrm{N} / \mathrm{A}$ \\
\hline
\end{tabular}

Gambar 2 spesifikasi baja s45c

\section{Variasi Pembebanan}

Penelitian ini menggunakan beberapa variasi pembebanan, baik pada arm maupun poros penyangga disc brake antara lain:

(1) Variasi pembebanan pada arm penyangga disc brake

a) Pembebanan saat kendaraan di naiki 1 orang penumpang

b) Pembebanan saat kendaraan di naiki 2 orang penumpang

(Di asumsikan berat badan masing-masing penumpang $65 \mathrm{Kg}$ )

(2) Besar putaran shaft mesin vespa PX 150 terhadap poros penyangga disc brake adalah $5700 \mathrm{rpm}$ (putaran maksimal).

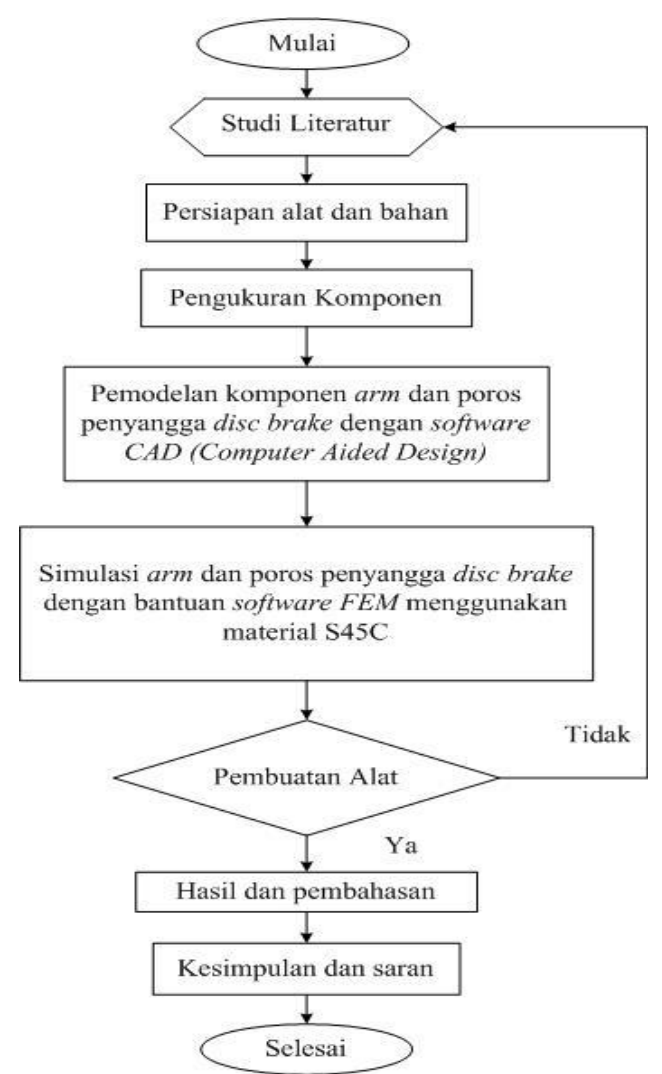

Gambar 3 diagram alir penelitian

\section{HASIL DAN PEMBAHASAN}

Hasil Simulasi pada Arm Penyangga Disc Brake

Berikut adalah hasil simulasi untuk arm penyangga disc brake berupa stress, strain dan displacement.

\section{Stress pada Arm penyangga Disc Brake dengan Von} Mises

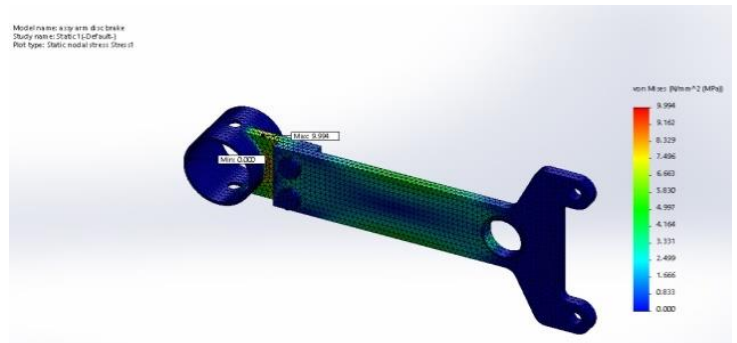

Gambar 4 hasil stress arm penyangga disc brake dengan beban $1274 n$

Dengan suatu pengetahuan hanya pada tegangan luluh (yield) dari suatu material, teori kegagalan ini memprediksi "ductile yielding" dibawah suatu kombinasi pembebanan, dengan akurasi lebih baik daripada teori-teori kegagalan lainnya. Teori kegagalan ini sering dikenal dengan teori kegagalan Von Mises. Selanjutnya dengan mengambil angka keamanan $\mathrm{N}$ $=4$, Maka:

$\sigma_{\mathrm{eq}} \leq \frac{S_{y}}{S F}=\frac{420}{4}$ 
$\sigma_{\text {eq }} \leq 105 \mathrm{Mpa}$

Tabel 1. Perbandingan tegangan maksimum pada arm penyangga disc brake dan tegangan yang diizinkan

\begin{tabular}{|c|c|c|c|}
\hline $\begin{array}{c}\text { Variasi } \\
\text { Pembebanan } \\
(\mathbf{N})\end{array}$ & $\begin{array}{c}\text { Tegangan } \\
\text { Maksimum } \\
\text { (Mpa) }\end{array}$ & $\begin{array}{c}\text { Tegangan yang } \\
\text { Diizinkan (Mpa) }\end{array}$ & Kesimpulan \\
\hline $\mathbf{6 3 7}$ & 4.997 & 105 & Aman \\
\hline $\mathbf{1 2 7 4}$ & 9.994 & 105 & Aman \\
\hline
\end{tabular}

\section{Hasil Simulasi Poros Penyangga Disc Brake}

Berikut adalah hasil simulasi untuk poros penyangga disc brake berupa stress, strain dan displacement.

\section{Stress pada Poros Penyangga Disc Brake dengan} Von Mises

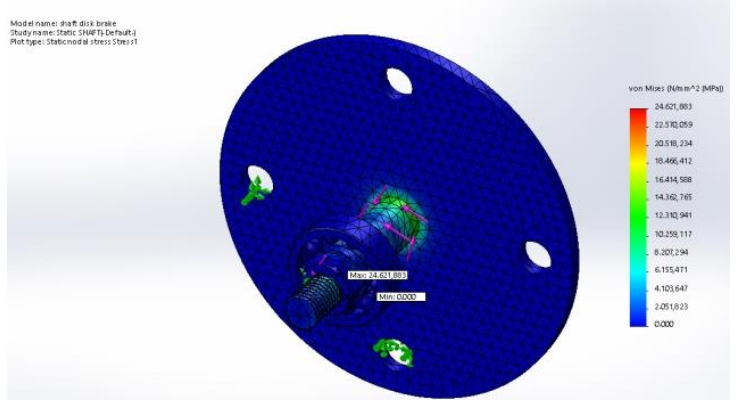

Gambar 5 Stress Pada Poros Untuk Putaran Maksimal 5700 Rpm

Dengan memakai teori yang sama, yaitu teori von mises dan memberikan nilai $\mathrm{N}$ sebesar 8 (beban dinamis), maka

$\sigma_{\mathrm{eq}} \leq \frac{S_{y}}{S F}=\frac{420}{8}$

$\sigma_{\mathrm{eq}} \leq 52.5 \mathrm{Mpa}$

Tabel 2. Perbandingan tegangan maksimum pada poros penyangga disc brake dan tegangan yang diizinkan

\begin{tabular}{|c|c|c|c|}
\hline $\begin{array}{c}\text { Kecepatan } \\
\text { Putaran } \\
\text { (Rpm) }\end{array}$ & $\begin{array}{c}\text { Tegangan } \\
\text { Maksimum } \\
\text { (Mpa) }\end{array}$ & $\begin{array}{c}\text { Tegangan yang } \\
\text { Diizinkan (Mpa) }\end{array}$ & Kesimpulan \\
\hline 5700 Rpm & 24.621883 & 52.5 & Aman \\
\hline
\end{tabular}

\section{PENUTUP}

\section{Kesimpulan}

Dari analisa yang telah dilakukan diatas, maka di dapat beberapa kesimpulan antara lain,

1. Dari hasil simulasi pengujian statik didapat angka keamanan untuk arm penyangga menggunakan material S45C adalah $105 \mathrm{Mpa}$ dan tegangan maksimal dari simulasi arm dengan beban satu penumpang (637 N) sebesar 4.997 Mpa, regangan 1.887e-5, dan displacement sebesar 2.896e-3 mm. Beban dua penumpang $(1274 \mathrm{~N})$, tegangan maksimal sebesar $9.994 \mathrm{Mpa}$, regangan sebesar 3.774e-5, dan displacement sebesar 5.791e-3 mm. Material bisa dikatakan aman dan bisa dijadikan bahan untuk pembuatan arm penyangga disc brake.

2. Untuk hasil simulasi pengujian statik pada poros penyangga menggunakan material S45C pada kecepatan maksimal 5700 Rpm didapat tegangan sebesar 24.621883 Mpa, regangan $7.705 \mathrm{e}-2$ dan displacement sebesar 1,381 mm. Apabila dibandingkan dengan nilai yang di iznkan teori von mises yaitu 52,5 Mpa, poros dengan material S45C bisa dikatakan aman apabila dijadikan bahan poros penyangga disc brake.

Saran

Hasil simulasi ini merupakan sarana pendukung untuk mendapatkan hasil yang optimal dalam analisa kekuatan material dengan bantuan software FEM. Sebaiknya apabila hendak melakukan pembuatan komponen dengan material tertentu, hendaknya mencari informasi tentang ketersediaan material. Penelitian ini masih banyak kekurangan, oleh karena itu saran untuk penelitian selanjutnya ialah dapat menganalisa beban terpusat atau beban linear pada arm penyangga disc brake serta getaran yang terjadi pada arm penyangga disc brake menggunakan software FEM yang lainnya.

\section{DAFTAR PUSTAKA}

Ian Hardianto Siahaan, H. (2008). Kineja Rem Tromol Terhadap Kinerja Rem Cakram Kendaraan Roda Dua Pada Pengujian Stasioner. TeknoSim, 397.

Mhd. Daud Pinem, S. M. (2010). Mekanika Kekuatan Material Lanjut. Bandung: Rekayasa Sains.

R.S. Khurmi, J. (n.d.). Library Genesis2M. Retrieved January 03, 2018, from gen.lib.rus.ec: https://libgen.pw/item/detail/id/779772 